\title{
Experimental Investigation of the Current Distribution in the Couplings of Moving Trains
}

\author{
Jonas Ekman, Member, IEEE, and Åke Wisten
}

\begin{abstract}
The transport of iron ore from the Swedish mining areas to the harbors is carried out by electric trains. In 2003, there was a dramatic increase in the number of bearings discarded due to electric current corrosion. No evident reason to this increase could be found and a project was initiated measuring electrical currents in engines and couplings as well as position and velocity of the train in an attempt to find countermeasures to the excess currents in the bearings. The root mean square magnitudes of the currents have been recorded and compared for different positions on the train, for different train configurations, and at different driving conditions. The results showed substantial electrical currents going through the couplings and much higher currents in modern trains with 30-tons axle load compared to old trains with 25-tons axle load.
\end{abstract}

Index Terms-Bearings, current distribution, current measurement, rail-transportation power systems.

\section{INTRODUCTION}

$\mathbf{T}$ HE transport of iron ore from the Swedish mining areas to the harbors in Narvik and Luleå is carried out by trains. Each train is usually made up of 52 to 66 cars, of three different types, pulled by two different engines. In the plan for the regular service of the wagons, each axle is treated as an individual, and the axles are removed from the cars, according a time- or distance- based schedule. Within this service schedule, during 2003, there was a dramatic increase in the number of bearings discarded because of current corrosion [1]. The damages showed typical signs of craters and fluting due to the passage of electric current [2]. It was obvious that many bearings had been exposed to high current densities, but not when or where on the 500-km track. It was not known whether the electrical breakdown of the bearings was still occurring since the bearings that were examined had all been running for five years or $500000 \mathrm{~km}$.

When the electric corrosion of the bearings was observed, it was not possible to judge whether the excess currents were caused by faults in the infrastructure, or by the rolling stock being faulty. Due to the many possible reasons, many areas had to be checked. For this purpose, a measuring program was initiated, checking the incoming and outgoing currents of the first cars of the trains, in order to find spots on the track where the

Manuscript received July 06, 2007; revised June 25, 2008. Current version published December 24, 2008. This work was supported by the LuossavaaraKiirunavaara AktieBolag (LKAB), Sweden, and Banverket, Sweden. Paper no. TPWRD-00401-2007.

The authors are with the Department of Computer Science and Electrical Engineering, Luleå University of Technology, Luleå 97187, Sweden (e-mail: jonas.ekman@1tu.se).

Color versions of one or more of the figures in this paper are available online at http://ieeexplore.ieee.org.

Digital Object Identifier 10.1109/TPWRD.2008.2005668 train currents were especially high, since this could indicate failing electrical installations. This is possible because one of the rails in the normal case is electrically unbroken and carries most of the return current from the engine to the power supply. In fact, a broken electric connection between two sections of the rail (a Z-connection), and some faulty ground connections between rail and poles, were detected this way. Therefore, all ground connections along the tracks were checked. Further, other investigations examined the seasonal variations of the ground water levels compared to the train currents and the recently discovered bearing damages [3].

This paper [4] was initiated, with the purpose of finding the normal current levels and current distributions in the ore trains and suggests countermeasures to avoid further damage by electric corrosion. The currents in the trains have not been measured before, but are indirectly considered to be small, because the bearings have only rarely shown traces of electric corrosion. It is known that bearing current densities $\geq 0.7 \mathrm{~A} / \mathrm{mm}^{2}$ may significantly reduce bearing life [1] for dc and low-frequency ac applications $(50 / 60 \mathrm{~Hz})$. Knowledge of the distribution of currents along the train were considered important in order to judge whether bypass conductors would help. An important parameter not studied before, which had to be included in this work, was the primary current of the engines (i.e., the total current into the engines from the contact wire), because all currents measured in the train should be considered in proportion to the total current.

The measurements showed coupling currents far above the expected levels and that the current distribution over a train is such that the bearings of the last part of the train tend to take more current than the bearings of the first part. Since the magnitudes of the currents are greatest when close to the engine and then reduced further back, it could be advantageous to make the couplings of the engine electrically isolated. This could reduce the total current into the train and consequently reduce the currents in the bearings.

In the paper, Section II gives a background to the railway system used for ore transport, current-induced bearing damages, and to the possible current paths in the train. Section III details the methods used for measuring position, velocity, altitude, primary currents, primary voltages, and coupling currents. Section IV gives results for current distributions in the couplings for four different measuring occasions and the paper finishes with conclusions in Section V.

\section{BACKGROUND}

\section{A. Railway System for Ore Transport}

1) Tracks: The railway system used for transporting the ore is a single track, mixed booster and autotransformer (BT and AT) 
TABLE I

CAR AND BEARING TYPES

\begin{tabular}{r|r|r|r} 
Car type & Bearing type [8] & Coupling type & Note \\
\hline \hline Fanoo [9] & Tapered bearing units & SA-3 (movable) & The latest car-type, 30 tons axle load. \\
& (TBU) & & No statistics on damage rate. \\
\hline Uno [10] & TBU & Janney, type F (solid) & $\begin{array}{r}\text { Relatively new car-type, 30 tons axle load. } \\
\text { Low damage rate (4.4\% for 2003-2006). }\end{array}$ \\
\hline Uad [9] & Spherical roller bearings & SA-3 (movable) & $\begin{array}{r}\text { Old cars, 25 tons axle load. Similar to Uadp. } \\
\text { High damage rate, see Fig. 2. }\end{array}$
\end{tabular}

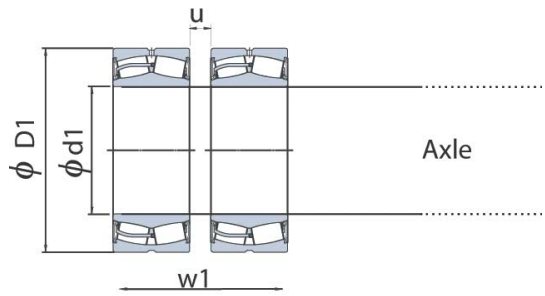

(a)

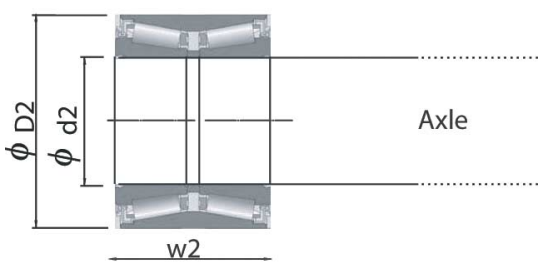

(b)

Fig. 1. Different bearing types. Spherical roller bearings in (a) Used in Uad cars with D1 $=250 \mathrm{~mm}, \mathrm{~d} 1=150 \mathrm{~mm}$, w1 $=176 \mathrm{~mm}$, and $\mathbf{u}=20 \mathrm{~mm}$ and tapered bearing unit in (b). Used in Fanoo/Uno cars with D2 $=250 \mathrm{~mm}, \mathrm{~d} 2=$ $157 \mathrm{~mm}$, and $\mathrm{w} 2=160 \mathrm{~mm}$.

system [5], [6]. Each $100 \mathrm{~km}$ along the tracks, there are electric power stations delivering $16 \mathrm{kV}-16.7 \mathrm{~Hz}$ alternating current to the overhead line using one of the rails (the S-rail) for the return current. The S-rail is connected to the iron foundations of the poles with copper wires, making a good grounding system. In case the S-rail changes sides, from left to right, there must be a crossover connection (Z-connection). Since the S-rail is well grounded, parts of the return current are running in the ground [7], but the ground currents are pulled back to the S-rail by means of autotransformers (AT) each at $10 \mathrm{~km}$. The overhead current runs in the primary of the 1:1 AT, and the S-rail-current in the secondary. Without the ATs, the ground currents would spread further away from the S-rail. Some portion of the return current also runs in the trains, but normally without causing damage to the bearings. The other rail, denoted by the I-rail, is divided into isolated sections, preset to 6-V DC voltage. When a train enters a certain section of the I-rail, this section is shorted to ground, making the voltage drop on the section, thereby defining the position of the train to the traffic-control center.

2) Bombardier IORE Engines: The ore is transported using either the old $7 \mathrm{MW}$, DM3 engines or by modern 10.8-MW, Bombardier-IORE engines. The Bombardier-IORE engines are connected in synchronized doubles. A single engine has six axles, and double engines have 12 axles. Each axle is separately driven by a frequency-controlled induction motor,

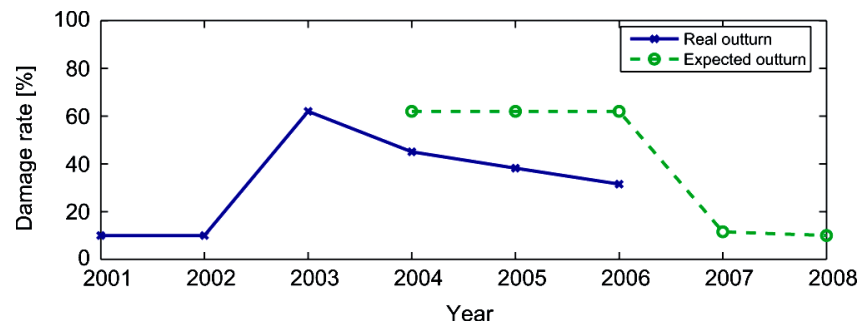

Fig. 2. Real and expected outturn (for a sudden event) for bearing damage rate.

with individual speed control for maximum nonslip torque. The maximum power consumed by an IORE engine-pair is 10.8 MW. Breaking can be either mechanical or electrical. Electrical breaking generates power to the overhead line. The primary current is forced down to the wheels of the engines through carbon brush contacts. It is also possible for currents to flow from the rails, through the chassis of the engine and into the coupling of the first car. The primary current is delivered by the overhead line to the engine, goes back through the rails, the train, and the ground. By measuring the currents in the couplings of the train, it was possible obtain a view of the paths of the return currents. In these experiments, the primary current and the currents in the couplings were measured simultaneously.

3) Ore Cars: The ore cars do not have any carbon brushes or other arrangements to save the bearings from currents. The same is true for all Swedish railway cars. The bearings of the ore cars are of two types, either 1) spherical roller bearings (SRBs) or 2) tapered bearing units (TBUs) as shown in Fig. 1. The tapered bearings have a larger contact areas than the spherical. The bearing oil is Shell Alvania 2760B. The ore cars are of mainly three types: 1) the old Uad-cars, 2) the new Uno-, and 3) Fanoo types, as further detailed in Table I. All cars have four axles, but they have different maximum loads. The old Uad cars take 25 tons/axle when loaded while the Uno and Fanoo types take 30 tons/axle when loaded. Subsequently, due to heavier loads, the primary current in the engines is significantly higher for the new, heavy trains with 68 Fanoo or Uno cars than the old trains with 52 Uad cars.

\section{B. Current-Induced Bearing Damages on the Ore Track}

In 2003, there was a dramatic increase of the number of bearings discarded because of current corrosion, see Fig. 2. The damages showed typical signs of light arcs (i.e., a darkened surface corrosion with regular patterns). It was obvious that 


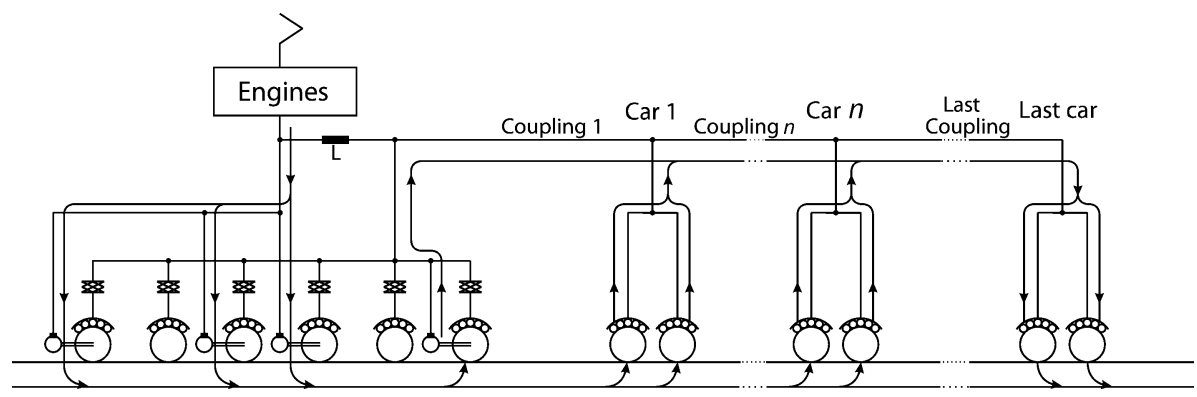

Fig. 3. Schematic sketch of the current path in the IORE engines, couplings, and Fanoo/Uno/Uad cars. L is a ground protection choke. The IORE has six engines in each of the two series electric locomotives. The cars have four axles but here, only two are shown.

many bearings had been exposed to high current densities, but not when or where on the 500-km track. It was not known whether the electrical breakdown of the bearings was still going on, since the examined bearings all had been running for five years or $500000 \mathrm{~km}$, according to the normal service schedule. The shortest possible service interval is two years.

From the maintenance system for the bearings, it is clear that the axles that are more active are more often checked. If most of the bearing damages occurred during a limited time, the "Real outturn" in Fig. 2 can be explained. But if we assume that all of the axles are running equally and, thus, are revised continuously, the outturn would look more like the "Expected outturn" in Fig. 2 and the damage rate would be equally high until all axles are repaired. An alternative explanation for the "Real outturn" can be that the bearing damages are due to a gradually impaired electric environment at the ore track. However, then the damage rate would be constant until the electric environment is improved, by itself or by human interaction. However, the last explanation has to be combined with another factor explaining the peak in the damage rate occurring during 2003 (e.g., if only some of the trains were damaged during a limited time and these were due for service in 2003).

When the current-induced damages were observed, broad activities began in order to find all possible reasons for high-current loads in the bearings. At this time, there had been many years of changes of the infrastructure and of the rolling stock. The traffic density had been gradually increasing, and so had the total tonnage of each train and the loads per axle. The exchange of the old DM3 engines in favor of the new IORE engines had started, leading to an increase of the available power per train from $7 \mathrm{MW}$ to $10.8 \mathrm{MW}$. The new engines also have electronic traction control and regenerative electric brakes, delivering electric power back to the supply system. Furthermore, the booster-transformer (BT) power-supply system has been exchanged for an autotransformer system (AT) along the tracks from Luleå to Gällivare [6], while the tracks from Gällivare to Narvik, still have the BT system.

Due to many possible reasons of the electrical corrosion, many areas had to be checked. Among these, a measuring program was initiated, checking the incoming and outgoing currents of the first car of the trains, in order to find spots of the track where the currents were especially high, since this would indicate failing electrical installations. In fact, a broken Z-connection, and some faulty ground connections were detected this way and, therefore, all ground connections along the tracks were checked.

This paper was initiated with the purpose of finding countermeasures to excess currents in the bearings. Knowledge of the distribution of currents along the train was considered important in order to judge whether bypass conductors would help. An important parameter not studied before, which had to be included in this work, was the primary current of the engines (i.e., the total current into the engines from the contact wire), because all currents measured in the train should be considered in proportion to the total current.

\section{Current Paths in the Train}

As an aid, a short description of the possible current path from the IORE engine connected to any car (Uad, Uno, Fanoo) is given in Fig. 3. The figure shows only one IORE engine for clarity. However, when used for ore transport, two IORE engines are connected in series. Each IORE locomotive has six motors, three axles supplied with carbon brushes to give a defined current path to the rail, two axles without carbon brushes, and one axle with carbon brushes connected to the chassis. In Fig. 3, a few possible current paths are indicated with arrows, similar to [11]. The figure shows the six IORE axles, rail, and the couplings to the cars (first, $n$ th, and last). The situation described is as expected when current is flowing from the locomotive into the first coupling, and added through the bearing of the first cars, traveling through the couplings of the train, and a portion of the current is distributed over the bearings of cars and the remainder exits through the bearings in the last car. The figure does not represent the situation when an AT is in front of the engines and the current is not going through the cars in the return path, see more on traction return current in AT electric railway systems in [7]. This case, with the changing current return paths due to AT passage, is seen as the train is driving and several examples can be seen in Section IV.

\section{MeAsuring Methods}

\section{A. Position, Velocity, and Altitude}

A global positioning system (GPS) receiver connected to one of the laptop computers continuously saved position coordinates, speed, and time. These GPS data were stored once per second. Since the currents and voltages in different positions along the train were measured by means of four different laptop 


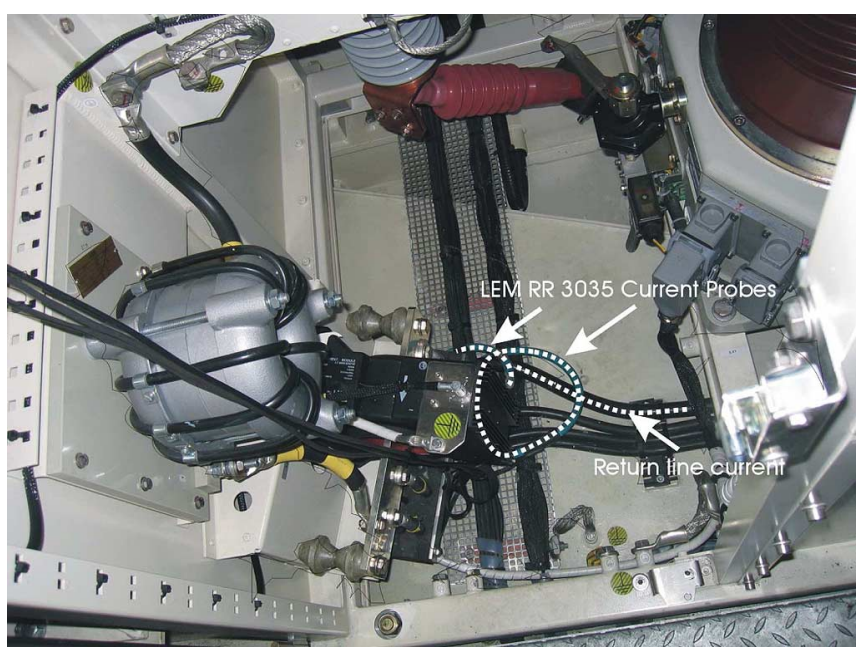

Fig. 4. Installation in the IORE engine to measure primary currents.

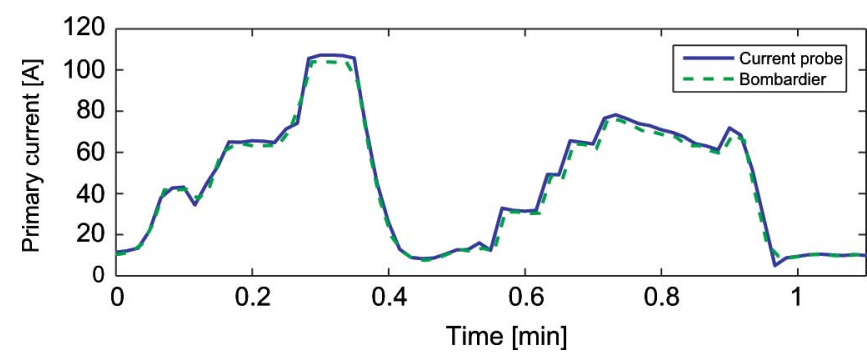

Fig. 5. Comparison of primary current measurements with Bombardier internal data.

computers equipped with measuring cards, each computer having its internal clock, these recordings had to be synchronized with respect to time.

\section{B. Primary Currents}

The total current from the contact wire to the engines is here denoted as primary current. Initial checking showed that both engines in series always took equally large currents, due to the motor control systems. Therefore, it was considered sufficient enough to measure the primary current in one of the two engines, as shown in Figs. 5 and 8-15. The primary current consumed by the engine was measured and monitored by means of a laptop computer connected to a current probe gripping a factory-installed cable in the high-voltage cabinet of the engine, see Fig. 4.

A verification of this measuring method for primary currents was conducted with Bombardier (IORE manufacturer) internal measuring methods showing good agreement, see Fig. 5, when using an LEM RR 3035 current probe. For other types of probes with other sensitivities, the measured primary current could have a bias level or show current peaks not registered by the Bombardier measuring methods.

For some tests, the primary voltage was also considered interesting and a measuring method was developed. This method involved probing two points in the IORE high-voltage cubicle and registering waveforms. This measuring method for primary voltage was compared with Bombardier internal measuring methods showing satisfactorily agreement, see Fig. 6. However,

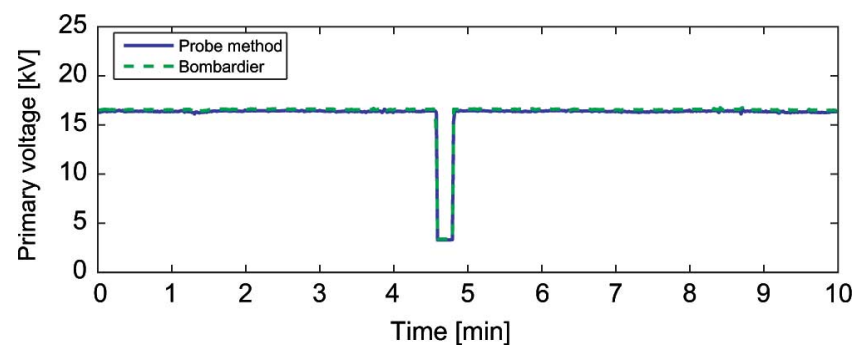

Fig. 6. Comparison of the primary voltages measurements with Bombardier internal data.

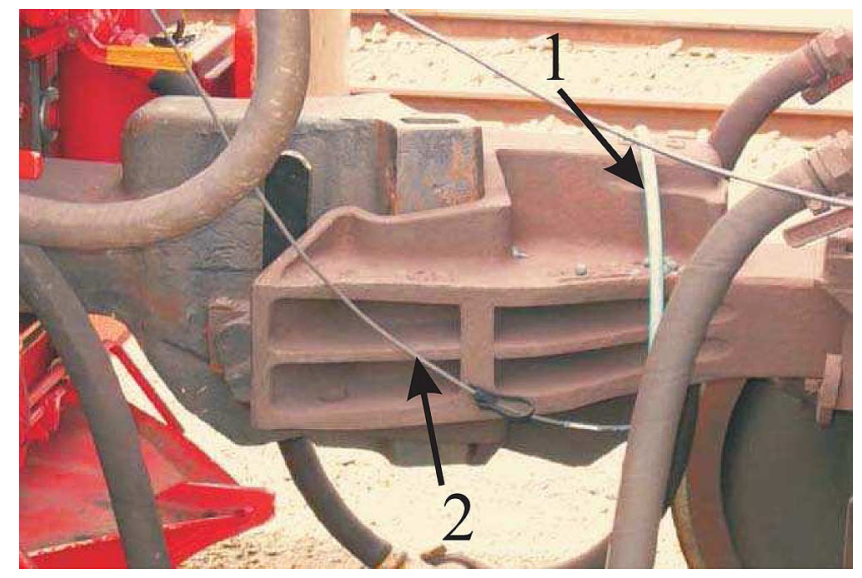

Fig. 7. Current probe of the Rogowski type, indicated by 1 measuring the current in the coupling between the engine and the first car. Cable connecting the current probe to the battery-powered amplifier (not shown), indicated by 2 .

the probing method, involving an attenuator and an amplifier, showed slightly lower voltage values $<1.2 \%$ than Bombardier data. In Fig. 6, the sudden drop from $16.6 \mathrm{kV}$ to $3.35 \mathrm{kV}$ is when the train enters a "zero-voltage-stretch."

\section{Coupling Currents}

The coupling currents were measured using the same type of current probe as for the primary currents as detailed in the previous paragraph. The arrangement is seen in Fig. 7 when measuring first coupling current. By tests, it was ensured that the method does not pick up and indicate (by magnetic-field couplings) large currents in nearby wires.

\section{RESUlts}

\section{A. Current Distribution for Iore-Engine With Uad-Cars}

The first results are for measurements conducted 2006-04-05, from 10:00 to 13:00 with measurement computers in the engine, and at the first, 20th, and 51st coupling. The train was $481.8 \mathrm{~m}$. long, has 52 Uad-cars giving a total weight of around 5516 tons. The first results, for 5-min driving, are shown in Fig. 8 where $400 \mathrm{~A}$ as the total primary current gives a first coupling current of $50.0 \mathrm{~A}, 20$ th coupling current of $37.0 \mathrm{~A}$, and the $51 \mathrm{st}$ coupling current is around 5.0 A. The stretch has no steep slopes and only two ATs are passed.

The results shown in Fig. 8 and the following tests showed that the currents flowing through the bearings decreased from the second car, but there was still considerable current in car 51 out of 52. As seen, the current was measured at the first coupling 

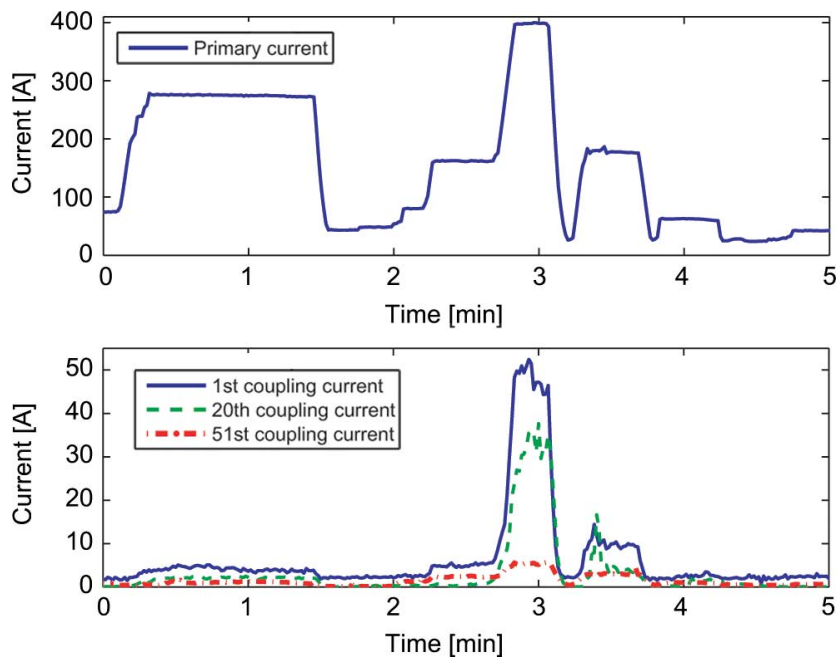

Fig. 8. Primary (top) and coupling (below) currents for the IORE engine with 52 Uad-cars.

TABLE II

CURRENT DISTRIBUTION IN 52 UAD CARS

\begin{tabular}{l|l|l|l}
$\begin{array}{l}\text { Coupling } \\
\text { no }\end{array}$ & $\begin{array}{l}\text { Cars be- } \\
\text { hind }\end{array}$ & $\begin{array}{l}\% \text { of total cur- } \\
\text { rent expected }\end{array}$ & $\begin{array}{l}\% \text { of total cur- } \\
\text { rent outcome }\end{array}$ \\
\hline \hline 1 & 52 & $100 \%^{\dagger}$ & $100 \%$ \\
20 & 33 & $63 \%$ & $74 \%$ \\
51 & 2 & $3.85 \%$ & $10 \%$ \\
$\dagger$ By definition. & &
\end{tabular}

to $50 \mathrm{~A}$, the current at the 20th coupling was measured to about $37 \mathrm{~A}$, and at the 51 st couplingm, it was about $5 \mathrm{~A}$ (i.e., $74 \%$ of the electrical current remained in the train where $62 \%$ remained in the total length of the train). Still $10 \%$ of the current remained where $4 \%$ remained in the train (see Table II and Fig. 8).

The second results for an IORE-engine with Uad-cars were collected 2006-03-12, 03:00 to 07:30, with the same type of train. Fig. 9 shows the results for primary current and first coupling current, note the scaling, for $30 \mathrm{~min}$. The coupling currents are less than $35.0 \mathrm{~A}$ for the 30-min period. Fig. 9(b) clearly shows the passage of an AT (Harrträsk) where the return current shifts in direction and starts to go along the train at min 18 , to the nearest AT, and not in front of the train. A steep climb, to the highest point of the track, finishes at min 28.

Further, a study was made to investigate the coupling currents due to mechanical dynamics of the couplings of the train. Typical results are shown in Fig. 10 where it is seen that the coupling currents follow the primary current for acceleration, deceleration, and constant speed. In the figure, the 2 nd and 8 th coupling currents refer to the front couplings of cars number 2 and 8 , see Fig. 3. The conclusion is that the mechanical forces on the couplings have no influence on the coupling currents. Neither do the coupling currents depend on whether the engines are consuming current or generating current (by its regenerative electric brake system). This is seen in Fig. 11 as follows.

Case 1) Steep climb. The train consumes high current from the overhead line (0 to $3 \mathrm{~min}$ ).

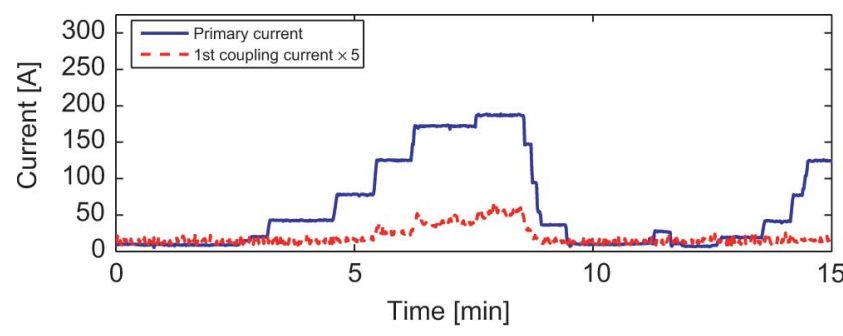

(a)

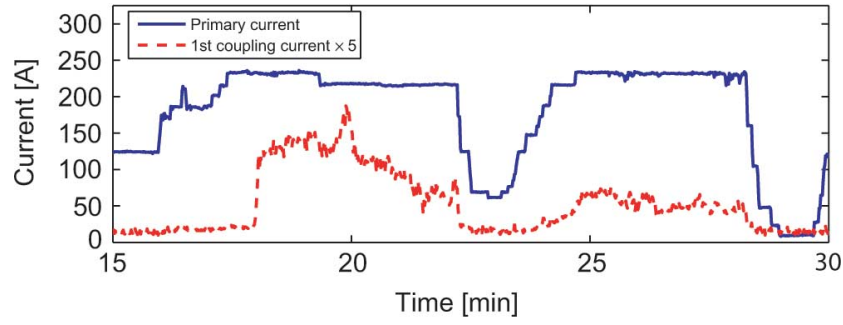

(b)

Fig. 9. Primary and first coupling current for the IORE-engine with 52 Uadcars measured during 30 min. Passage of an AT at min 18 and steep climb finishing at $\min 28$.
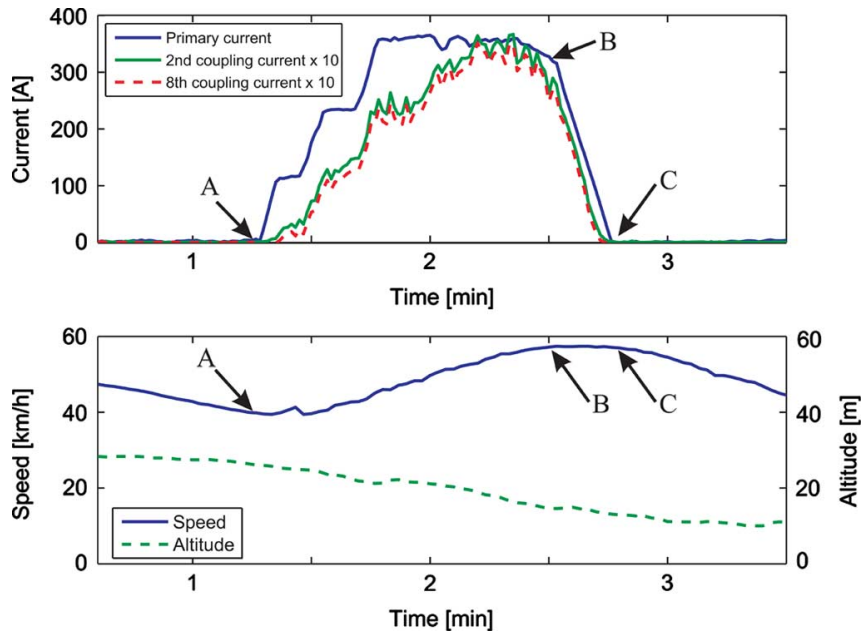

Fig. 10. Primary and coupling currents (top figure) for deceleration (before A), acceleration (between A and B), constant speed (between B and C), and deceleration (after C).

Case 2) Approaching the top of the hill. A small amount of current is drawn from the overhead line ( 3 to 3.8 $\min )$.

Case 3) Driving downhill. Regenerating current back to the electric system (3.8 to $5.35 \mathrm{~min}$ ) when the train is moving downhill and the electrical brake system is used.

Note that the figures show rms current values which means that consumed and regenerated currents are positive.

\section{B. Current Distribution for the IORE-Engine with Fanoo-Cars}

For the remaining test, the new IORE-engines with the Fanoocars are studied. The measurements were conducted on March 27,2006 , from 02:00 to 03:00 with measurement computers in the engine, and at the first, 11th, 41st, and 65th coupling. The train was $725.8 \mathrm{~m}$ long, and had 66 Uad-cars, giving a total 

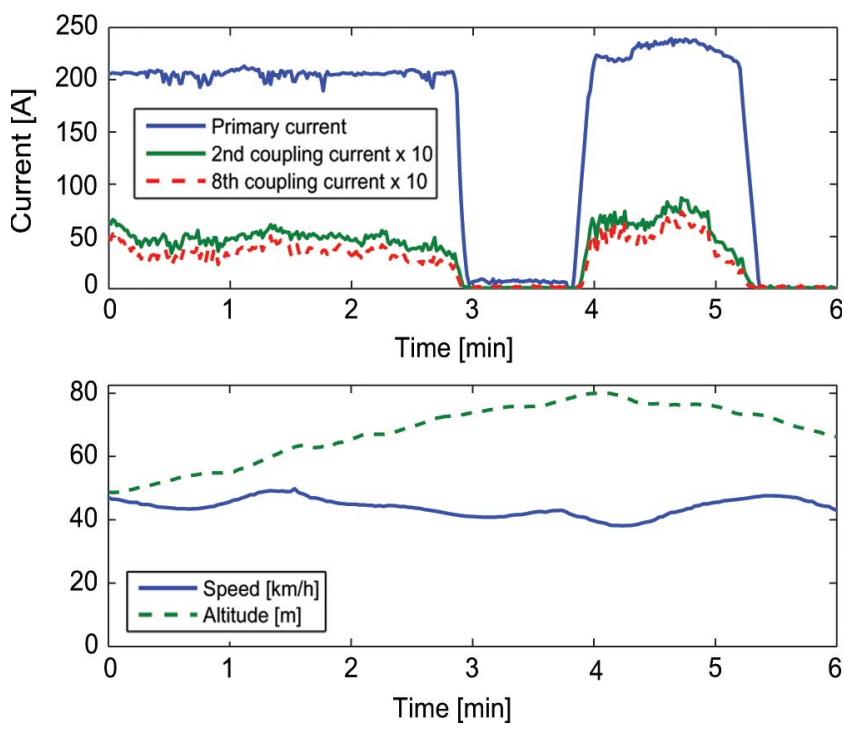

Fig. 11. Primary and coupling currents (top figure) when current is drawn (0 to $3.8 \mathrm{~min}$ ) from and regenerated $(3.8$ to $5.35 \mathrm{~min})$ to the electrical system. The bottom figure shows speed and altitude for the uphill movement ( 0 to $4 \mathrm{~min}$ ) and the downhill movement (4 to $6 \mathrm{~min}$ ).
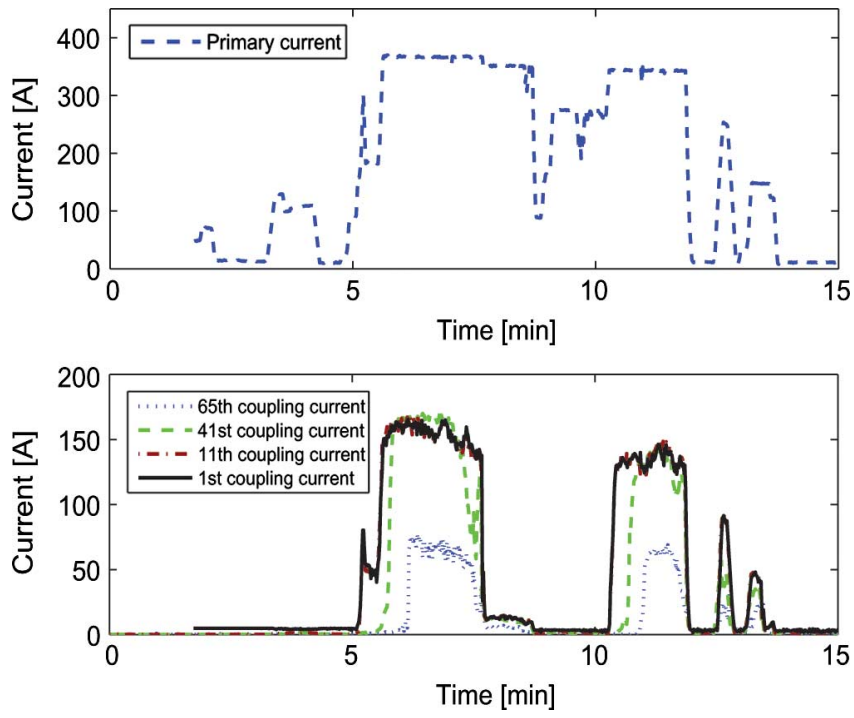

Fig. 12. Primary and coupling currents for the long and heavy IORE+ Fanoo train. Passing two ATs and arriving at a station (Gällivare) at min 15.

weight of around 8315 tons. The first results, for 15-min driving is shown in Fig. 12, just after departure from Vitåfors. Two ATs are passed at min 5 and min 10.30 explaining the time shift in the coupling currents. Of notice are the high coupling currents, compared to the IORE-engine with Uad-cars, in the order of $160.0 \mathrm{~A}$ in the first, 11th, and 41st couplings. The current in the 65th coupling is $75.0 \mathrm{~A}$ maximum for this stretch.

Since the amount of electrical current flowing through the couplers was close to constant back to car 41, there was apparently no current leakage through the bearings in the first $2 / 3$ of the train. Therefore, the majority of the coupling current leaves the train through the bearings of the last one-third of the train. Around min 7, in Fig. 12, 150 A must have gone through the bearings of the last part of the train, between car 41 and the last car, number 66, and 50 A through the bearings of the last two

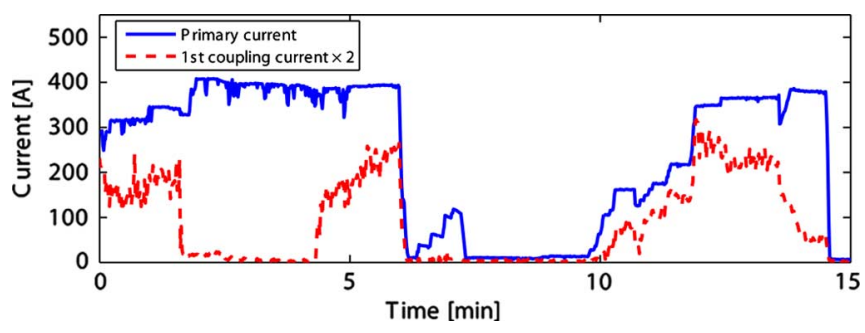

Fig. 13. Primary and first coupling current for the long and heavy IORE + Fanoo train. The train stops at $\min 7$ at a station (Gällivare).

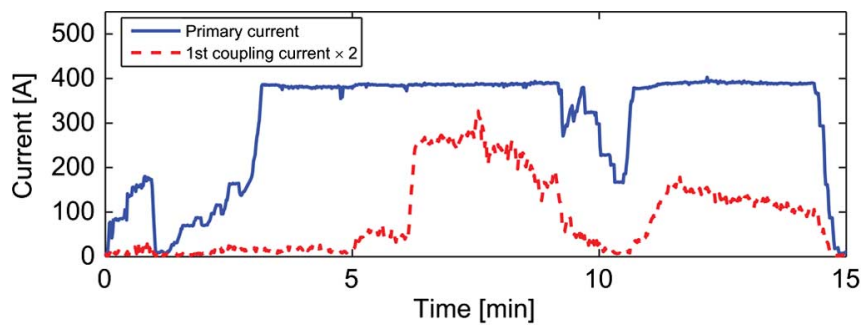

(a)

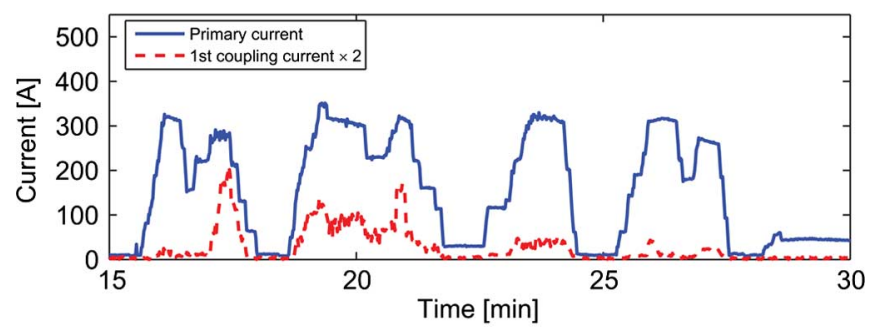

(b)

Fig. 14. Primary and first coupling current for the long and heavy IORE + Fanoo train. (a) Climb of a slope. (b) Normal driving condition.

cars, number 65 and 66. Each wheel axle is equipped with two bearings in each end, thus, a total number of 16 bearings per car, and each bearing of the two last cars had to carry at least $50 / 32=1.6 \mathrm{~A}$, and probably much more in case of uneven distribution.

The second results for an IORE-engine with Fanoo-cars were collected 2006-03-11, 14:12 to $18: 15$, with the same type of train. Fig. 13 shows the results for primary current and first coupling current, notice the scaling, just after departure from Vitåfors. The train stops at $\min 7$ at a station (Gällivare).

The following results, in Fig. 14, are collected directly after the results in Fig. 13 and show the climb of a slope (Harrträskbacken), in Fig. 14(a) and the normal driving condition in Fig. 14(b).

Interestingly, the results in Fig. 14(a), for the IORE + Fanoo train, can be directly compared with the results in Fig. 9(b) showing the same climb for the IORE + Uad train. These figures are displayed together in Fig. 15 for clarity. It is clearly seen that the first coupling current is substantially lower for the IORE + Uad train, 37.0 A, compared to the IORE + Fanoo train $165.0 \mathrm{~A}$.

The current flow in the train, the rails, and the ground are governed by the electrical impedances in the cars and in the surrounding structures. If, for instance, the mutual inductance between the overhead line and the train were dominating, the 


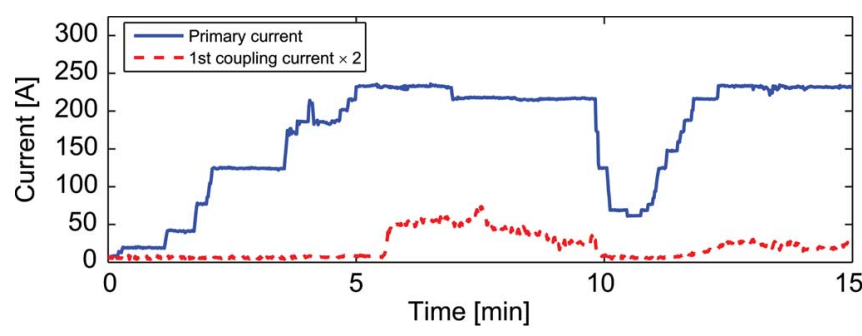

(a)

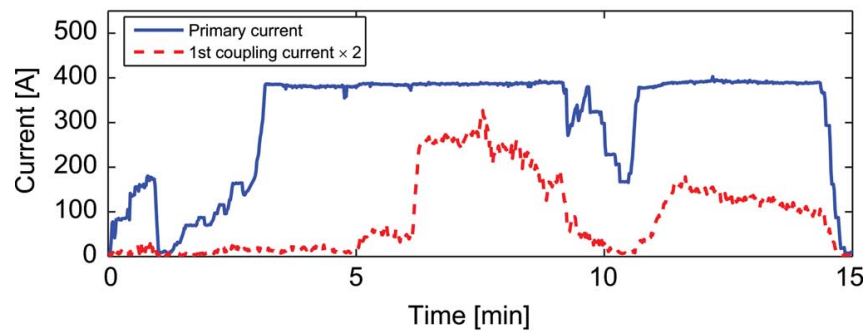

(b)

Fig. 15. Primary and first coupling current for the IORE - Uad (a) and for the IORE + Fanoo (b) train when climbing a steep slope.

TABLE III

CURRENT DisTRIBUTION IN 66 FANOO-CARS

\begin{tabular}{l|l|l|l}
$\begin{array}{l}\text { Coupling } \\
\text { no }\end{array}$ & $\begin{array}{l}\text { Cars be- } \\
\text { hind }\end{array}$ & $\begin{array}{l}\% \text { of total cur- } \\
\text { rent expected }\end{array}$ & $\begin{array}{l}\% \text { of total cur- } \\
\text { rent outcome }\end{array}$ \\
\hline \hline 1 & 66 & $100 \%{ }^{\dagger}$ & $100 \%$ \\
11 & 56 & $85 \%$ & $100 \%$ \\
41 & 26 & $39 \%$ & $100 \%$ \\
65 & 2 & $3 \%$ & $47 \%$ \\
$\dagger$ By definition. & &
\end{tabular}

current in the train would have a tendency to follow the train as long as possible, and pass down to the rails through the bearings of the last cars. If, on the other hand, the same mutual inductance were negligible, the current through the bearings would be equally distributed over the whole length of the train. In such a case, each car would take $1 / 52=2 \%$ of the current into the first coupling (e.g., the current in coupling no. 20, with 33 cars behind, would carry $33 / 52=63 \%$ of the current), and so on. According to Tables II and III, this is apparently not the case, and a more sophisticated electrical model is needed. The authors are working on such a model, which will be presented in another paper.

\section{Comments}

The new trains IORE + Fanoo or IORE + Uno showed a tendency of carrying the current quite far back. The current distribution was not equal, but the currents through the bearings were concentrated on the last cars of the trains. Fig. 16 shows the current distribution in the coupling versus the relative position in the train for the IORE + Uad and IORE + Fanoo trains from Sections IV-A and IV-B. In the figure, the current in the individual couplings has been integrated over time and related to the first (integrated) coupling current. It is obvious that the bearings of the last cars have to conduct more current than the bearings in the beginning of the train.

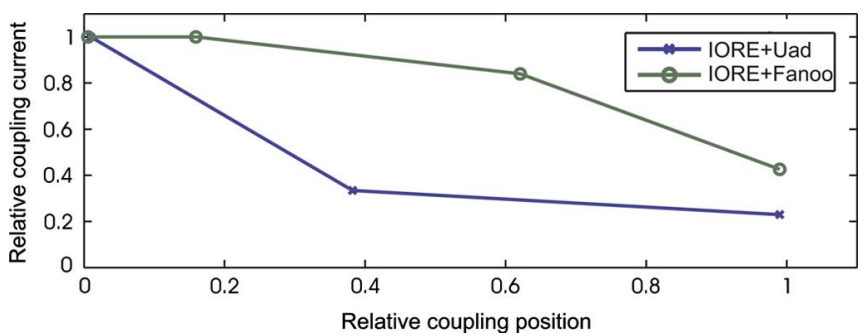

Fig. 16. Plot for relative current distribution in couplings versus relative position along the train ( 0 - first coupling, 1 -last coupling).

The magnitudes of the currents from the engine into the first car were compared for an old Uad train with 52 cars and a modern Fanoo train with 66 cars. The load of the Uad train was 25 tons per axle, but the load of the Fanoo train was 30 tons per axle. Both trains ran on the same route, from Vitåfors to Luleå-Sandskär. The recordings showed much bigger currents in the modern Fanoo trains than in the older Uad trains. The maximum current flowing through the Fanoo train was measured to about $165 \mathrm{~A}$, when the total primary current was close to $800 \mathrm{~A}$, compared to the maximum current measured in the Uad train to about $37 \mathrm{~A}$, when the total primary current was about 480 A (i.e., of the total primary current, $8 \%$ of the primary current ran in the first coupling of the Uad-train, compared to $21 \%$ in the first coupling of the Fanoo train). One conclusion can be that the electrical resistance is lower in the Fanoo trains than in the Uad trains. The reason is probably that the new tapered roller bearing units (TBUs) have lower electrical resistance than the old spherical roller bearings. As shown in Fig. 1, the bearing types have different geometries.

\section{CONCLUSION}

The measurements indicate that the total electrical resistance of a modern Uno or Fanoo train is substantially lower than the total resistance of an old Uad train. Taking into consideration the different number of cars (66 and 52, respectively), the conclusion is still the same. Since the new, heavy trains (IORE + Fanoo and IORE + Uno ) show no indication of abnormal damage rates for bearing damage by current corrosion, this is an important fact in the further work. The actual damage rate to be noted for the Fanoo-cars is unknown at this date due to the recent introduction.

The current distribution over a train is such that the bearings of the last part of the train tend to take more current than the bearings of the first part. Since the magnitudes of the currents are greatest close to the engine and then reduced further back, it would be advantageous to make the couplings of the engine electrically isolated. This would substantially reduce the total current into the train and consequently reduce the currents in the bearings. An alternative to the isolated coupling is, for example, a dedicated, last car with good electrical connection from car to rail, thus allowing the majority of the current to go through the train and out through the last car.

The high rate of current-induced damages continued during the following years, and is still (2007) higher than normal, but gradually decreasing. However, the work on countermeasures will continue during 2007. 


\section{ACKNOWLEDGMENT}

The authors would like to thank T. Nordmark, B. Rytting, and all other staff at LKAB and MTAB for their skilful and effective cooperation in this project.

\section{REFERENCES}

[1] A. Muetze, A. Binder, H. Vogel, and J. Hering, "What can bearings bear?," IEEE Ind. Appl. Mag., vol. 12, no. 6, pp. 57-64, Nov./Dec. 2006.

[2] "Rolling bearing damage-recognition of damage and bearing inspection," FAG. Schaeffler Group. [Online]. Available: http://www.fag. com.

[3] A. Wahlberg, A. Nilsson, and J. Nyberg, "Lagerskador orsakade av strömgenomgång," Banverket, Sweden, 2004, BRNB 2004:10.

[4] ̊̊ Wisten and J. Ekman, Studier av orsaken till strömskador på järnvägsvagnars hjullager och möjliga motåtgärder, Luleå Univ. Technol., Luleå, Sweden, 2006, 2006:12.

[5] F. J. Sollerkvist and G. Varju, "A comparison of the AT and BT railway systems from an induction point of view, using a multiconductor simulation," presented at the EMC Roma, Rome, Italy, 1998.

[6] A. Bülund, U. Hellström, and G. Varju, "Changing from booster transformer system to auto transformer system in the Kiruna-Rltsi-Svappavaara line in Sweden," presented at the 2nd Int. Conf. Electric Railway Systems, Berlin, Germany, 1999.

[7] A. Mariscotti, P. Pozzobon, and M. Vanti, "Distribution of the traction return current in AT electric railway systems," IEEE Trans. Power Del., vol. 20, no. 3, pp. 2119-2128, Jul. 2005.

[8] "Taper roller bearings" SKF. [Online]. Available: http://www.skf.com/ portal/skf/home/products?

[9] "Kockums industrier AB." [Online]. Available: http://www.kockumsindustrier.se.
[10] "Transwerk." [Online]. Available: http://www.transwerk.co.za/.

[11] Stromführung im Bereich von Radsatz-Wälzlagern in Schienenfahrzeugen, Deutsche Norm, DIN VDE 0123, 1985.

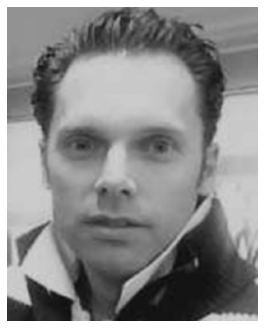

Jonas Ekman (M'02) was born in Boden, Sweden, in 1972. He received the Ph.D. degree in electrical engineering from Luleå University of Technology, Luleå, Sweden, in 2003.

From 2003 to 2007, he was a Researcher at Luleå University of Technology, Luleå, Sweden. From 2005 to 2006, he conducted Postdoctoral Research in full-wave, time-domain, and PEEC modeling at the EMC Laboratory, University of L'Aquila, L'Aquila, Italy. In 2008, he was appointed Associate Professor at Luleå University of Technology. His research interests are in computational electromagnetics, in particular, the use of the PEEC method for realistic electromagnetic modeling.

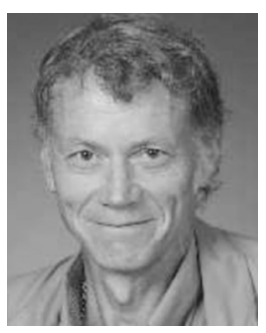

Åke Wisten was born in Ramsele, Sweden, in 1946. He received the M.Sc. degree in engineering physics from the Lund Institute of Technology, Lund, Sweden, in 1972.

He was a Teacher in electromagnetic fields with the Lund Institute of Technology from 1972 to 1991. During 1991-2006, he was a Teacher in electronics, electromagnetic compatibility (EMC), and related topics at Luleå University of Technology, Luleå, Sweden, where he was a Manager of the EMC Center from 1996 to 2006. His research interests are in EMC and the power-supply systems of electrical railways. 